\title{
The control of bile acid pool size: Effect of jejunal resection and phenobarbitone on bile acid metabolism in the rat $^{1}$
}

\author{
H. Y. I. MOK, P. M. PERRY, AND R. HERMON DOWLING ${ }^{2}$ \\ From the Departments of Medicine and Surgery and the MRC Intestinal Malabsorption Group, Royal \\ Postgraduate Medical School, Hammersmith Hospital, London
}

SUMMARY In patients with cholesterol gallstones, there is a diminished bile acid pool and the bile becomes supersaturated with cholesterol. Medical treatment has been aimed at re-expanding the pool to improve cholesterol solubility in bile but as yet the factors controlling the size of the bile acid pool 'are unknown. Therefore the role of the liver and intestine in controlling bile acid pool size in the rat was studied and the effect of experimental expansion of the pool on bile acid metabolism and bile lipid composition examined. Bile acid absorption was increased from ileum made hyperplastic by previous jejunectomy and hepatic bile acid synthesis was increased by phenobarbitone treatment.

Both jejunal resection and phenobarbitone significantly increased the size of the bile acid pool from $32.2 \pm$ SEM $0.94 \mu$ moles/100 $\mathrm{g}$ body weight to $42.2 \pm 1.71$ and $44.4 \pm 2.03$ respectively. However, the effects of these experimental manipulations on bile acid secretion rate, enterohepatic cycling frequency, and synthesis rates were quite different. Jejunectomy caused a $56 \%$ increase in bile acid secretion and more rapid cycling of the bile acid pool but the enhanced absorption did not depress bile acid synthesis. In contrast, phenobarbitone markedly increased synthesis from $14.5 \pm$ $1.42 \mu$ moles. $100 \mathrm{~g} \mathrm{BW}^{-1} .24 \mathrm{hr}^{-1}$ to $25.9 \pm 3.19$ but there was no significant change in bile acid secretion and the choleresis seen after phenobarbitone was mainly due to an increase in the bile acid-independent fraction of bile flow.

In these experimental studies in the rat, expansion of the bile acid pool did not significantly change bile lipid composition or cholesterol solubility in bile.

A reduced bile acid pool is one of the major metabolic defects in patients with cholesterol gallstones (Vlahcevic, Bell, Buhac, Farrar, and Swell, 1970; Brunner, Horak, and Grabner, 1973; Danzinger, Hofmann, Thistle, and Schoenfield, 1973; Heaton, 1973; Arnësjo and Ståhl, 1973). Bile from such patients is usually supersaturated with cholesterol (Admirand and Small, 1968) perhaps as a result of the diminished bile acid pool (Swell, Bell, and Vlahcevic, 1971; Vlahcevic, Bell, Gregory, Buker, Juttijudata, and Swell, 1972; Grundy, Metzger, and Adler, 1972) since re-expansion of the pool by feeding chenodeoxycholic acid improves cholesterol

'Presented in part at a meeting of the Medical Research Society, 17 February 1973 (Mok et al, Clin. Sci., 44, 19-20 P).

'Requests for reprints to R.H.D., Gastroenterology Unit, Department of Medicine, Guy's Hospital Medical School, SE1

Received for publication 15 January 1974. solubility in bile (Thistle and Schoenfield, 1971) and promotes gallstone dissolution (Danzinger, Hofmann, Schoenfield, and Thistle, 1972; Bell, Whitney, and Dowling, 1972; Danzinger et al, 1973). The size of the bile acid pool is, therefore, of fundamental importance in the pathogenesis of gallstones, but yet the factors which control the pool size are largely unknown.

The bile acid pool may be defined as the total mass of bile acids in the enterohepatic circulation (EHC) and theoretically both intestinal reabsorption and hepatic synthesis could influence the size of the pool. To study the factors controlling pool size, we modified both intestinal bile acid absorption and hepatic bile acid synthesis in the rat and examined not only the resultant changes in pool size but also other related aspects of bile acid metabolism. The effect of expansion of the bile acid pool on bile lipid 
composition was also studied. This paper reports our findings.

\section{Materials and Methods}

\section{EXPERIMENTAL ANIMALS}

Female Wistar rats with an initial body weight of 150 to $220 \mathrm{~g}$ were used throughout. There were three groups of animals:

(1) A jejunal resection group (seven rats) in which bile acid absorption was increased from ileum made hyperplastic by jejunectomy eight to 12 weeks before study - a situation which we have recently shown causes supranormal bile acid absorption (Perry, Mok, and Dowling, 1973).

(2) A phenobarbitone-treated group (seven rats) which was given the microsomal enzyme-inducing agent phenobarbitone $(1 \mathrm{mg} / \mathrm{ml}$ drinking water) for a minimum of five days before study in an attempt to increase hepatic bile acid synthesis. On average, adult rats drink $15-25 \mathrm{ml} /$ day. The estimated intake of phenobarbitone was therefore comparable to the doses previously used for enzyme induction in the rat. However, on a body weight basis these doses cannot be compared to the therapeutic doses of phenobarbitone used in man.

(3) A control group of nine rats with an intact small intestine, which received no treatment.

\section{STUDIES OF BILE ACID METABOLISM}

The bile acid pool size, secretion, and 'basal' hepatic synthetic rates were measured in acute bile fistula studies using Myant and Eder's (1961) modification of Eriksson's (1957) original 'washout' technique. The derivation of these measurements is illustrated diagrammatically in figure 1 .

\section{OPERATIVE TECHNIQUE}

To avoid the effects of starvation on bile acid metabolism, the animals were studied in the nonfasting state and to exclude changes in diurnal rates of bile acid synthesis, each experiment was begun at a constant time (between 8.30 am and 9.30 am). Under light ether anaesthesia, the abdomen was opened, the distal end of the common bile duct firmly ligated and a fine polyethylene cannula (OD $0.80 \mathrm{~mm}$, ID $0.40 \mathrm{~mm}$ Portex polythene tubing) inserted into the proximal end of the duct. The abdomen was closed and the rat was then placed in a Bollman restraining cage in which it rapidly recovered from anaesthesia. Bile was collected at two-hour intervals for a total of 16 to 24 hours by means of an automatic fraction collector and the volume of the samples was recorded. Daily bile volume was extrapolated from that obtained during the first 12 hours. The 24-hour bile volume

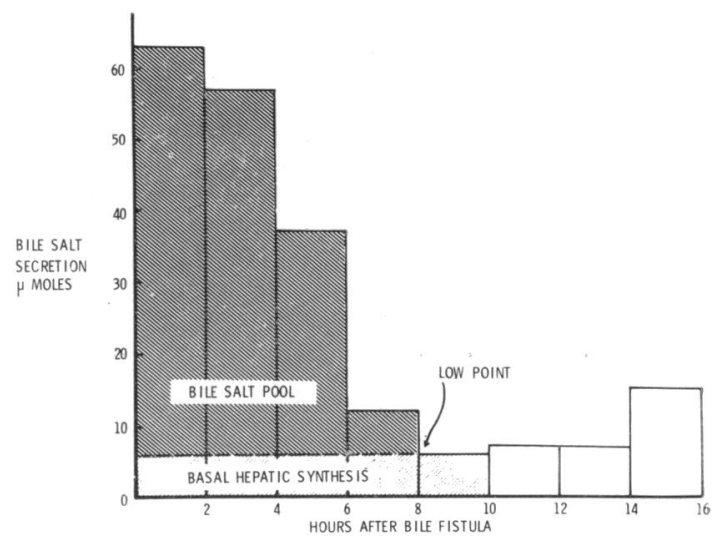

Fig 1 Example of bile salt secretion rate during 16 hours after cannulation of the common bile duct in the rat. The figure illustrates the 'washout' pattern and how the various components of the enterohepatic circulation may be calculated. The bile salt pool (the dark crosshatched area) is the total amount of bile salt produced from the time of cannulation until the low point is reached minus the contribution due to basal hepatic synthesis. The bile salt secretion rate is calculated from the amount secreted during the first two hours after cannulation.

could equally well have been extrapolated from the initial two hour collection, but the 12-hour period was arbitrarily chosen for two reasons. First, while it is mandatory to use the initial two-hour period to calculate bile acid secretion, as the pool is "washed out', bile volume falls much less than bile acid secretion since only the bile-acid-dependent fraction of bile flow is affected. Secondly, the use of the 12-hour period minimizes the minor fluctuations in bile volume which may occur immediately after cannulation of the common bile duct. The rat was allowed $4.3 \%$ dextrose in saline and commercial food pellets (41B) ad libitum.

\section{BILE ACID SECRETION RATE}

The bile acid secretion rate per 24 hours is defined as the total bile acid output (mainly due to recycled but also to a small extent to newly synthesized bile acids), as calculated by extrapolation from the output during the first two hours after cannulating the bile duct. The validity of this extrapolation is supported by the results of studies using an experimental model in bile fistula Rhesus monkeys (Dowling, Mack, Picott, Berger, and Small, 1968). In these studies, it was shown that the bile acid secretion rate during the first two hours after acute interruption of the enterohepatic circulation closely approximates to the normal secretion rate measured over the preceding five to seven days in the steady 
state with a virtually intact enterohepatic circulation (Dowling, Mack, and Small, 1970; Campbell, Burgess, Roberts, and Dowling, 1972).

\section{BASAL SYNTHESIS RATE AND BILE ACID POOL SIZE}

Although the initial secretion rate is maintained because of the bile acids remaining in the enterohepatic circulation at the time of creating the bile fistula, once the pool has been washed out the secretion rate falls to reach a low point when any bile acid appearing has been newly synthesized by the liver. This represents the "basal rate of hepatic bile acid synthesis'-theratenormally required to replenish bile acid loss from the enterohepatic circulation.

The 'bile acid pool' ( $\mu$ moles $/ 100 \mathrm{~g}$ body weight) is the amount of bile acid obtained from the time of inserting the fistula until the 'low point' on the washout curve, minus the contribution due to basal hepatic synthesis.

Since the secretion rate is a product of pool size and the number of times the pool circulates per day, and since both secretion rate and pool size may be derived, the 'circulation frequency' (number of EH cycles/24 hours) may be calculated by dividing secretion rate by pool size.

BILE ACID AND BILE LIPID DETERMINATIONS The biliary bile acid concentration was measured enzymatically using $3 \alpha$ hydroxysteroid dehydrogenase (Admirand and Small's 1968 modification of the method of Talalalay, 1960). Phospholipid concentration was calculated from the total lipid phosphorous content of bile (Bartlett, 1959). Cholesterol concentration was determined after lipid extraction of bile with chloroform:methanol $(2: 1 \mathrm{v} / \mathrm{v})$ using a modification of Carr and Drekter's method (1956). The results for each individual bile lipid in the first two-hour bile sample were then expressed as a molar ratio (moles \%) of all three lipids (Admirand and Small, 1968).

LIVER WEIGHT

As an index of the overall mass of hepatic tissue available for bile acid synthesis, the livers were removed at the end of each experiment and their fresh weights measured.

\section{STATISTICAL ANALYSIS}

The results are expressed as means \pm SEMs. The significance of differences between the results for the different experimental groups were analysed with the non-paired Student's $t$ test.

\section{Results}

BILE ACID POOL SIZE

The results of bile acid pool size are shown in figure 2. Jejunal resection and phenobarbitone treatment both increased the size of the bile acid pool from a mean of 32.2 ( \pm SEM 0.94) $\mu$ moles $/ 100$ $\mathrm{g}$ body weight in control rats to $42 \cdot 2( \pm 1 \cdot 71)$ after resection and $44.4( \pm 2.03)$ in the phenobarbitone group, representing increases of 31 and $37 \%$ respectively. The results in the experimental groups were both significantly greater than control values $(t=5.128 ; P<0.001$ and $t=5.450 ; P<0.001$ respectively), but there was no significant difference between the results for the resection and the phenobarbitone-treated groups.

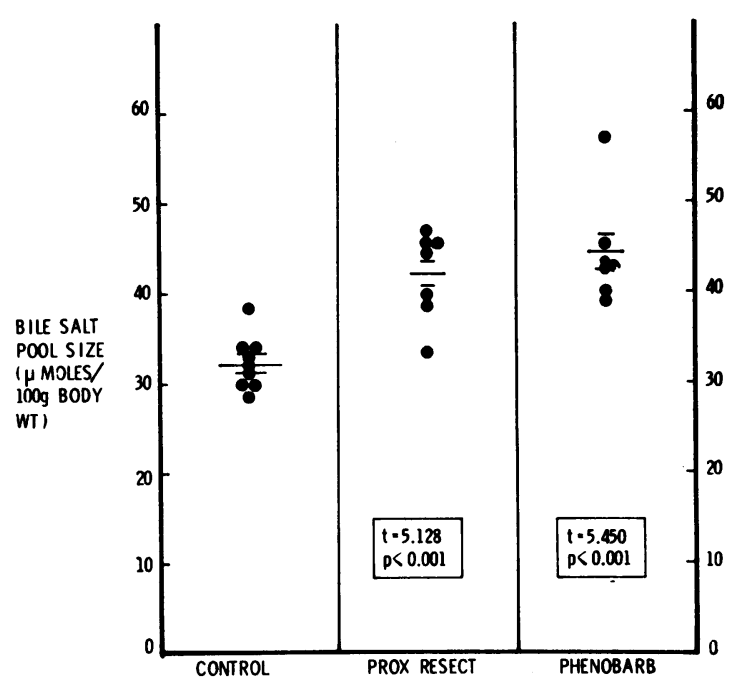

Fig 2 Bile salt pool size (means \pm SEMs) in control rats, in animals eight to 12 weeks after proximal small bowel resection, and after at least five days' treatment with phenobarbitone.

BILE ACID SECRETION

While both experimental groups had comparable increases in bile acid pool size, the effect of proximal resection and phenobarbitone on the 24-hour bile acid secretion rates was quite different (table I).

\begin{tabular}{lll}
\hline & $\begin{array}{l}\text { Bile Acid Secretion } \\
\left(\mu \text { moles.100 } \mathrm{g} \mathrm{BW} W^{-1} .24\right. \\
\left.h r^{-1}\right)\end{array}$ & $\begin{array}{l}\text { Statistical } \\
\text { Significance }\end{array}$ \\
\hline $\begin{array}{l}\text { Control } \\
\begin{array}{l}\text { Proximal } \\
\text { resection }\end{array}\end{array}$ & $185 \pm 9.4$ & - \\
$\begin{array}{l}\text { Phenobarbitone } \\
\text { Ten }\end{array}$ & $289 \pm 9.6$ & $\mathrm{P}<0.001$ \\
\hline
\end{tabular}

Table I Effect of proximal resection and phenobarbitone on bile acid secretion

Jejunal resection caused a highly significant increase in the bile acid secretion rate, the mean value of 289 $\mu$ moles $100 \mathrm{~g} \mathrm{BW}^{-1} .24$ hours $^{-1}$ being $56 \%$ greater 
than the control value, but in spite of the greater pool size, there was only a slight $(15 \%)$ increase in the daily secretion rate of the phenobarbitone-treated rats, and this did not differ significantly from the results in control animals.

Phenobarbitone caused a marked choleresis, the 24-hour bile volume increasing from $5.3 \pm 0.23$ $\mathrm{ml} / 100 \mathrm{~g}$ body weight in control rats to $7 \cdot 3 \pm 0.49$ after treatment, and this difference was statistically significant $(t=3.711 ; P<0.005)$. At the same time there was a fall in bile acid concentration from $367 \pm 33.2 \mu$ moles $/ 100 \mathrm{ml}$ bile in control animals to $298 \pm 18.4$ in the treated rats. The choleresis seen after phenobarbitone, therefore, is partly due to a stimulation of the bile acid independent fraction of bile flow, as defined by Erlinger, Dhumeaux, Benhamou, and Fauvert (1969).

\section{FREQUENCY OF CIRCULATION OF THE BILE ACID POOL}

In control rats, the mean number of enterohepatic cycles per day was $5.7( \pm 0.25)$. The different secretion rates seen in the experimental groups, in the face of comparable increases in pool size, were reflected in the frequency of circulation of the bile acid pool. Jejunal resection caused a proportionately greater increase in secretion rate than in pool size, indicating a significantly more frequent circulation of the bile acid pool $(6.9 \pm 0.36$ times/day; $t=$ $2.740 ; \mathrm{P}<0.02)$ through the shortened intestine. In contrast, phenobarbitone treatment had a relatively greater effect on pool size than on secretion rate so that the number of enterohepatic cycles was reduced

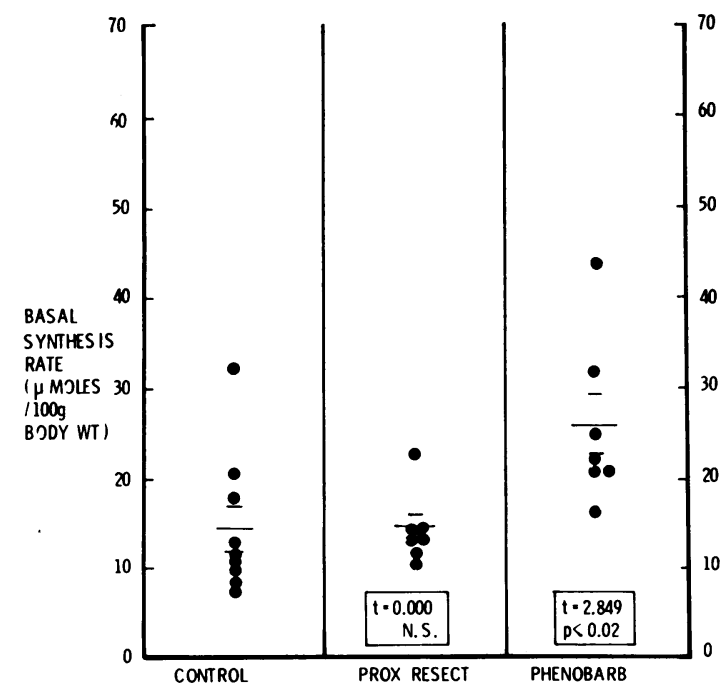

Fig 3 Basal rates of bile salt synthesis in control and experimental groups (see legends to figures 1 and 2). to $4 \cdot 8 \pm 0 \cdot 18 /$ day and this reduction was significantly less than control values $(t=2.922 ; P<0.02)$.

BASAL HEPATIC BILE ACID SYNTHESIS RATE The results from measurements of basal hepatic bile acid synthesis are shown in figure 3 . In spite of the increased intestinal bile acid absorption seen after jejunectomy, there was no significant depression of hepatic bile acid synthesis, the mean value in the resected animals of $14.5( \pm 2.42) \mu$ moles. $100 \mathrm{~g}^{-1}$ 24-hours ${ }^{-1}$ being the same as that in control rats $(14.5 \pm 1.42)$. However, there was a net increase in hepatic bile acid synthesis in the phenobarbitonetreated animals, which was $79 \%$ above the control value.

\section{LIVER WEIGHT}

The results of fresh wet weight of liver are shown in table II. There was no difference between the results for control and jejunectomized rats, but the $25 \%$ increase in liver weight after phenobarbitone treatment was significantly greater than control values.

\begin{tabular}{lll}
\hline & $\begin{array}{l}\text { Liver Weight } \\
(\mathrm{g} / 100 \mathrm{~g} \mathrm{BW})\end{array}$ & $\begin{array}{l}\text { Statistical } \\
\text { Significance }\end{array}$ \\
\hline Control & $3 \cdot 2 \pm 0.04$ & - \\
Proximal resection & $3 \cdot 1 \pm 0.04$ & $\mathrm{NS}$ \\
Phenobarbitone & $4.0 \pm 0.08$ & $\mathrm{P}<0.001$ \\
\hline
\end{tabular}

Table II Effect of proximal resection and phenobarbitone on liver weight

BILE LIPID COMPOSITION (TABLE III)

Expansion of the bile acid pool in both experimental groups did not improve cholesterol solubility in bile. The rat has low cholesterol secretion and its bile lipid composition is well within the micellar zone of cholesterol solubility (Admirand and Small, 1968).

\section{Discussion}

These studies have shown that, in the rat, when intestinal bile acid absorption is increased from ileum made hyperplastic by jejunectomy or when net hepatic bile acid synthesis is increased by phenobarbitone, the size of the bile acid pool increases significantly.

Theoretically, the direct methods used in the present studies should have advantages over the indirect techniques currently available to study bile acid metabolism in man. For example, the bile acid pool may be measured by the isotope dilution technique (Lindstedt, 1957) and reasonably physiological estimates of bile acid secretion have been 


\begin{tabular}{llll}
\hline & \multicolumn{2}{l}{ Molar Ratio (\%) } & \\
\cline { 2 - 4 } & Bile Acid & Phospholipid & Cholesterol \\
\hline Control & $90.8 \pm 0.83$ & $8.4 \pm 0.80$ & $0.8 \pm 0.04$ \\
Proximal resection & $89.4 \pm 0.71$ & $9.4 \pm 0.71$ & $1 \cdot 1 \pm 0.18$ \\
Phenobarbitone & $90.9 \pm 1.06$ & $8.2 \pm 0.95$ & $0.9 \pm 0.16$ \\
\hline
\end{tabular}

Table III Effect of proximal resection and phenobarbitone on bile lipid composition

obtained by intestinal perfusion methods (Go, Hofmann, and Summerskill, 1970; Grundy et al, 1972; Brunner et al, 1973). However, both methods depend on many assumptions. The relatively simple Eriksson 'washout' technique used here also makes many assumptions, and, to date, there have been no critical studies validating these methods and comparing measurements of bile acid pool size with both the washout and with the isotope dilution techniques. We are currently conducting such studies and these results will be the subject of further communications.

The present observation that phenobarbitone stimulates the bile acid independent fraction of bile flow (Erlinger et al, 1969) confirms the results of earlier studies (Berthelot, Erlinger, Dhumeaux, and Preaux, 1970; Gerolami, Crotte, Vigne, Mule, and Grangier, 1972; Redinger and Small, 1973), but expansion of the bile acid pool after phenobarbitone has only been noted once before (Redinger and Small, 1973). There is no evidence that phenobarbitone affects intestinal bile acid absorption (Ostrower, Coan, and Kern, 1973) and it seems likely that the expanded bile acid pool and increased basal synthetic rates are due to a direct effect on hepatic bile acid synthesis.

The mechanism whereby phenobarbitone affects bile acid synthesis is uncertain. In some strains of rats, Einarsson and Johansson (1968), Boyd, Scholan, and Mitton (1969), and Mitropoulos and Balasubramaniam (1973) found no change in hepatic cholesterol $7 a$ hydroxylase (the rate-limiting enzyme in bile acid synthesis from cholesterol) specific activity, but in Wistar rats, Shefer, Hauser, and Mosbach $(1968 ; 1972)$ claimed that there was an increase in this enzyme activity per mg hepatic microsomal protein. Whether or not cholesterol $7 a$ hydroxylase specific activity changes, the present finding of a $25 \%$ increase in hepatic mass after phenobarbitone, which has been noted previously (Roberts and Plaa, 1967; Stäubli, Hess, and Weibel, 1969; Berthelot et al, 1970), is adequate alone to explain the net increase in synthesis and expansion of the bile acid pool.

The effect of jejunal resection on bile acid pool size has not been studied previously but there is considerable evidence that jejunectomy causes marked changes in ileal structure and absorptive function. Within two weeks of jejunal resection, the ileal mucosa becomes hyperplastic (Dowling and Booth, 1967) and the increased mucosal surface results in enhanced absorption of substances which are normally absorbed diffusely throughout the small intestine, such as water, electrolytes, amino acids, mono- and disaccharides (Dowling and Booth, 1967; Tilson and Wright, 1970; Weser and Hernandez, 1971; Bury, 1972; Perry et al, 1973). For substances with active transport systems confined to the ileum, the adaptive ileal hyperplasia presumably increases the number of active transport sites since we have recently shown that jejunectomy causes supranormal bile acid (Perry, White, and Dowling, 1972) and vitamin $B_{12}$ (MacKinnon, 1973; Elias, MacKinnon, Short, and Dowling, 1973) absorption.

The bile acid pool size has not been measured in patients with jejunal resection, but in the analogous situation of coeliac disease, where mucosal damage is often confined to the duodenum and jejunum, Low-Beer, Heaton, Pomare, and Read (1973) found that the bile acid pool was often much greater than normal. They suggested that this was due to a sluggish gallbladder as a result of reduced cholecystokinin release from the diseased mucosa. However, ileal adaptation with supranormal bile acid absorption was not directly excluded and it remains possible that enhanced active bile acid transport contributed to the expanded bile acid pool. Certainly the ileal absorption of other substances such as water, steroids, and methionine (Schedl and Clifton, 1961; Schedl, Pierce, Rider, and Clifton, 1968) and intrinsic factor bound vitamin $B_{12}$ (Elias et al, 1973) may be supranormal in coeliac disease.

The more rapid enterohepatic cycling after jejunectomy was probably due to more rapid transit of bile acids through the shortened intestine. We have previously shown that the mean transit time of barium from stomach to colon falls from a normal value of $137 \pm \mathrm{SEM} 11 \mathrm{~min}$ to $117 \pm 15$ min after jejunectomy (Dowling, 1968). This $15 \%$ change in transit time closely corresponds to the $17 \%$ increase in circulation frequency seen in the present studies after resection. Although resection of 
the jejunum removes an area where bile acids are absorbed by passive diffusion, the increased active transport from the ileum must have outweighed any loss of absorption by diffusion from the proximal intestine with an overall increase in absorption. Why the net increase in absorption failed to suppress hepatic bile acid synthesis is unknown but we are currently studying this by measuring cholesterol $7 a$ hydroxylase specific activity in the livers of jejunectomized rats.

While jejunal resection and phenobarbitone treatment both increased the size of the bile acid pool, there was no change in bile lipid composition. However, the very low levels of biliary cholesterol in the rat make it difficult to relate changes in bile lipid composition in this species to questions of cholesterol solubility and gallstone formation in man. In many species (including man) a diminished bile acid pool and/or a low bile acid secretion rate result in bile which is supersaturated with cholesterol (Nilsson and Scherstén, 1969; Vlahcevic et al, 1970; Dowling, Mack, and Small, 1971; Wheeler and King, 1972; Dowling, Bell, and White, 1972; Northfield and Hofmann, 1973). However, the corollary, implicit in the present studies, that a supranormal pool will reduce the saturation of bile with cholesterol does not necessarily follow. In fact, the results of recent perfusion studies in man show that, although an increase in bile acid secretion rate from low to normal values changes bile from being supersaturated to undersaturated with cholesterol, once the normal cholesterol:bile acid + phospholipid ratio has been reached, it remains constant and even with high bile acid secretion rates there is no further reduction in the saturation of bile with cholesterol (Northfield, personal communication; Northfield, La Russo, Thistle, and Hofmann, 1973). It seems surprising, therefore, that in Rhesus monkeys with an intact enterohepatic circulation and normal pretreatment bile acid pool sizes and secretion rates, Redinger and Small (1973) found that phenobarbitone increased bile cholesterol solubility in two out of three animals. More recently, these authors suggested that treatment with phenobarbitone also reduces the saturation of bile with cholesterol in man. We have been unable to confirm this: in two patients with gallstones, therapeutic doses of phenobarbitone (90-180 mg/day) for three weeks did not change bile lipid composition and in three further patients on long-term treatment with phenobarbitone $(90 \mathrm{mg} /$ day) for epilepsy, bile lipid composition was similar to that in healthy control subjects (Mok and Dowling, unpublished observations).

These experimental studies have provided basic information about the role of the liver and intestine in regulating the size of the bile acid pool. Although reduction in cholesterol saturation of bile may occur when a diminished pool is re-expanded by treatment with chenodeoxycholic acid, the present results show that expansion of a normal pool to supranormal levels does not further improve cholesterol solubility in bile.

We are grateful to Mrs June White for technical help, to Mrs Hazel Creed who typed the script and to the staff of the animal house for care of the experimental animals. This work was carried out during the tenure of a Commonwealth medical fellowship (HYIM). Thanks are also due to Weddel Pharmaceuticals Limited and to the MRC Intestinal Malabsorption Group for financial support (RHD).

\section{References}

Admirand, W. H., and Small, D. M. (1968). The physicochemica basis of cholesterol gallstone formation in man. J. clin. Invest., 47, 1043-1052.

Arnësjo, B., and Ståhl, E. (1973). Taurocholate metabolism in patients with cholesterol gallstones. Scand. J. Gastroent., 8, 369-375.

Bartlett, G. R. (1959). Phosphorus assay in column chromatography. J. biol. Chem., 234, 466-468.

Bell, G. D., Whitney, B., and Dowling, R. H. (1972). Gallstone dissolution in man using chenodeoxycholic acid. Lancet, 2, 1213-1216.

Berthelot, P., Erlinger, S., Dhumeaux, D., and Preaux, A. M. (1970). Mechanism of phenobarbital-induced hypercholeresis in the rat. Amer. J. Physiol., 219, 809-813.

Boyd, G. S., Scholan, N. A., and Mitton, J. R. (1969). Factors influencing cholesterol $7 a$-hydroxylase activity in the rat liver. Advanc. exp. Med. Biol., 4, 443-456.

Brunner, H., Horak, W., and Grabner, G. (1973). Bile acid output during digestion in gallstone patients. (Abstr.). Digestion, 8, 431.

Bury, K. D. (1972). Carbohydrate digestion and absorption after massive resection of the small intestine. Surg. Gynec. Obstet., 135, 177-187.

Campbell, C. B., Burgess, P., Roberts, S. A., and Dowling, R. H. (1972). The use of rhesus monkeys to study biliary secretion with an intact enterohepatic circulation. Aust. N.Z. J. Med., 2, 49-56.

Carr, J. J., and Drekter, I. J. (1956). Simplified rapid technic for the extraction and determination of serum cholesterol without saponification. Clin. Chem., 2, 353-368.

Danzinger, R. G., Hofmann, A. F., Schoenfield, L. J., and Thistle, J. L. (1972). Dissolution of cholesterol gallstones by chenodeoxycholic acid. New Engl. J. Med., 286, 1-8.

Danzinger, R. G., Hofmann, A. F., Thistle, J. L., and Schoenfield, L. J. (1973). Effect of oral chenodeoxycholic acid on bile acid kinetics and biliary lipid composition in women with cholelithiasis. J. clin. Invest., 52, 2809-2821.

Dowling, R. H. (1968). Compensatory mechanisms in the small intestine. MD Thesis, Queen's University, Belfast.

Dowling, R. H., Bell, G. D., and White, J. (1972). Lithogenic bile in patients with ileal dysfunction. Gut, 13, 415-420.

Dowling, R. H., and Booth, C. C. (1967). Structural and functional changes following small intestinal resection in the rat. Clin. Sci., 32, 139-149.

Dowling, R. H., Mack, E., Picott, J., Berger, J., and Small, D. M (1968). Experimental model for the study of the enterohepatic circulation of bile in rhesus monkeys. J. Lab. clin. Med., 72, 169-176.

Dowling, R. H., Mack, E., and Small, D. M. (1970). Effects of controlled interruption of the enterohepatic circulation of bile salts by biliary diversion and by ileal resection on bile salt secretion, synthesis and pool size in the rhesus monkey. J. clin. Invest., 49, 232-242.

Dowling, R. H., Mack, E., and Small, D. M. (1971). Biliary lipid secretion and bile composition after acute and chronic inter- 
ruption of the enterohepatic circulation in the rhesus monkey. IV. Primate biliary physiology. J. clin. Invest., 50, 1917-1926. ,

Einarsson, K., and Johansson, G. (1968). Effect of phenobarbital on the conversion of cholesterol to taurocholic acid. Europ. J. Biochem., 6, 293-298.

Elias, E., MacKinnon, A. M., Short, M. D., and Dowling, R. H. (1973). Factors controlling ileal adaptation after proximal small bowel resection and in coeliac disease. (Abstr.). Europ. J. clin. Invest., 3, 226.

Eriksson, S. (1957). Biliary excretion of bile acids and cholesterol in bile fistula rats: bile acids and steroids. Proc. Soc. exp. biol. (N.Y.), 94, 578-582.

Erlinger, S., Dhumeaux, D., Benhamou, J. P., and Fauvert, R. (1969). La sécrétion biliaire du lapin: preuves en faveur d'une importante fraction indépendante des sels biliaires. Rev. franc. Etud. clin. biol., 14, 144-150.

Gerolami, A., Crotte, C., Vigne, J. -L., Mule, A., and Grangier, M. (1972). Modifications of a bile salt independent fraction of bile flow and phospholipid secretion in bile. (Abstr.). Digestion, 6, 277-278.

Go, V. L. W., Hofmann, A. F., and Summerskill, W. H. J. (1970). Simultaneous measurements of total pancreatic, biliary and gastric outputs in man using a perfusion technique. Gastroenterology, 58, 321-328.

Grundy, S. M., Metzger, A. L., and Adler, R. D. (1972). Mechanisms of lithogenic bile formation in American Indian women with cholesterol gallstones. J. clin. Invest., 51, 3026-3043.

Heaton, K. W. (1973). Gallstone formation. In Proceedings of the Ninth Symposium on Advanced Medicine, edited by G. Walker, pp. 363-378. Pitman, London.

Lindstedt, S. (1957). The turnover of cholic acid in man: bile acids and steroids 51. Acta physiol. scand., 40, 1-9.

Low-Beer, T. S., Heaton, K. W., Pomare, E. W., and Read, A. E. (1973). The effect of coeliac disease upon bile salts. Gut, 14, 204-208.

MacKinnon, A. M. (1973). Small bowel adaptation after intestinal resection in guinea pig with functional adaptation of vitamin $\mathrm{B}_{12}$ absorption. Amer. J. dig. Dis., 18, 576-582.

Mitropoulos, K. A., and Balasubramaniam, S. (1973). Personal communication.

Myant, N. B., and Eder, H. A. (1961). The effect of biliary drainage upon the synthesis of cholesterol in the liver. J. Lipid Res., 2, 363-368.

Nilsson, S., and Scherstén, T. (1969). Importance of bile acids for phospholipid secretion into human hepatic bile. Gastroenterology, 57, 525-532.

Northfield, T. C., and Hofmann, A. F. (1973). Biliary lipid secretion in gallstone patients. Lancet, $1,747-748$.

Northfield, T. C., La Russo, N. F., Thistle, J. L., and Hofmann, A. F. (1973). Effect of chenodeoxycholic acid therapy on biliary lipid secretion in gallstone patients. (Abstr.). Gastroenterology, 64, 780.

Ostrower, V. S., Coan, P., and Kern, F., Jr. (1973). The effect of pheno- barbital $(\mathrm{Pb})$ on ileal absorption of cholic acid (CA). (Abstr.) Gastroenterology, 64, 781.

Perry, P. M., Mok, H. Y. I., and Dowling, R. H. (1973), Bile acid absorption after small bowel resection in the rat. In Proceedings of the International Conference on Intestinal Adaptation, Titisee, Germany. Schattauer, Stuttgart (in press).

Perry, P. M., White, J., and Dowling, R. H. (1972). Bile salt absorption following small bowel resection in the rat. (Abstr.) Gut, 13, 845.

Redinger, R. N., and Small, D. M. (1973). Primate biliary physiology. VIII. The effect of phenobarbital upon bile salt synthesis and pool size, biliary lipid secretion, and bile composition. J. clin. Invest., 52, 161-172.

Roberts, R. J., and Plaa, G. L. (1967). Effect of phenobarbital on the excretion of an exogenous bilirubin load. Biochem. Pharmacol., $16,827-835$.

Schedl, H. P., and Clifton, J. A. (1961). Kinetics of intestinal absorption in man: normal subjects and patients with sprue. (Abstr.) J. clin. Invest., 40, 1079-1080.

Schedl, H. P., Pierce, C. E., Rider, A., and Clifton, J. A. (1968), Absorption of 1-methionine from the human small intestine. J. clin. Invest., 47, 417-425.

Shefer, S., Hauser, S., and Mosbach, E. (1968). $7 a$ hydroxylation of cholesterol by rat liver microsomes. J. Lipid Res., 9, 328-333.

Shefer, S., Hauser, S., and Mosbach, E. H. (1972). Stimulation of cholesterol $7 a$-hydroxylase by phenobarbital in 2 strains of rats. J. Lipid Res., 13, 69-70.

Stäubli, W., Hess, R., and Weibel, E. R. (1969). Correlated morphometric and biochemical studies on the liver cell. II. Effects of phenobarbital on rat hepatocytes. J. Cell Biol.,, 42, 92-112.

Swell, L., Bell, C. C., Jr., and Vlahcevic, Z. R. (1971). Relationship of bile acid pool size to biliary lipid excretion and the formation of lithogenic bile in man. Gastroenterology, 61, 716-722.

Talalay, P. (1960). Enzymic analysis of steroid hormones. Meth. biochem. Anal., 8, 119-143.

Thistle, J. L., and Schoenfield, L. J. (1971). Lithogenic bile among young Indian women: lithogenic potential decreased with chenodeoxycholic acid. New Engl. J. Med., 284, 177-181.

Tilson, M. D., and Wright, H. K. (1970). Adaptation of functioning and bypassed segments of ileum during compensatory hypertrophy of the gut. Surgery, 67, 687-693.

Vlahcevic, Z. R., Bell, C. C., Jr., Buhac, I., Farrar, J. T., and Swell, L. (1970). Diminished bile acid pool size in patients with gallstones. Gastroenterology, 59, 165-173.

Vlahcevic, Z. R., Bell, C. C., Gregory, D. H., Buker, G., Juttijudata, P., and Swell, L. (1972). Relationship of bile acid pool size to the formation of lithogenic bile in female Indians of the Southwest. Gastroenterology, 62, 73-83.

Weser, E., and Hernandez, M. H. (1971). Studies of small bowel adaptation after intestinal resection in the rat. Gastroenterology, $60,69-75$.

Wheeler, H.'O., and King, K. K. (1972). Biliary excretion of lecithin and cholesterol in the dog. J. clin. Invest., 51, 1337-1350. 